\title{
Acute Effects of Dichloroacetate in the Depancreatized Dog: Glucose Synthesis and Turnover
}

\author{
G. L. Searle, J.M. Felts and R. Shakelford \\ The Veterans Administration Medical Center and the Department of Physiology, University of California, San Francisco, California, USA
}

\begin{abstract}
Summary. Blood glucose turnover (entry and removal rates) and the rate of recycling of radiolabelled glucose carbon into newly synthesized blood glucose have been evaluated before and acutely after the administration of dichloroacetate to depancreatized dogs. Blood glucose concentration began to decline immediately after dichloracetate administration and fell to new steady state levels within $1.5-3 \mathrm{~h}$. Analysis of blood glucose kinetics during the decline demonstrated a $52 \%$ (average) reduction in the rate of hepatic glucose supply. Glucose supply remained reduced over the duration of these studies
\end{abstract}

( $3-4.5 \mathrm{~h})$. Glucose turnover in the steady state following dichloroacetate administration averaged $62 \%$ of pretreatment values. Cori cycle activity was depressed by $63 \%$ after dichloroacetate administration. The results of these studies are consistent with the hypothesis that a major mechanism underlying the hypoglycaemic action of this drug is the inhibition of glucose synthesis.

Key words: Dichloroacetate, inhibition, glucose synthesis, hypoglycaemic agent.
Investigations with dichloroacetate (DCA) indicate that this rather simple compound has marked effects on glucose metabolism. DCA (di-isopropylammonium salt) was shown to reduce blood glucose concentration in the diabetic but not in the normal rat [1,2]. An early hypothesis to explain this blood glucose-lowering action was that the drug inhibited the oxidation of non-esterified fatty acids (NEFA). This would lead to a fall in tissue citrate levels, which would lead in turn to the deinhibition of phosphofructokinase and an acceleration of glycolysis [3]. The original observations detailing these actions in rat hemi-diaphragms [2] and in intact rats [3], have been confirmed in other studies [4]. Another biochemical basis for the action of DCA was proposed by Whitehouse and Randle [5] who demonstrated that DCA activated pyruvate dehydrogenase in heart muscle. Studies by Alberti et al. have shown that DCA could ameliorate or reverse the lactic acidosis observed with biguanide therapy [6], a predictable consequence of pyruvate dehydrogenase activation which would shunt pyruvate into the Krebs cycle. A further consequence of such action has been demonstrated in rats starved for $24 \mathrm{~h}$ : namely that DCA acutely restricts glucogenic substrate (lactate and alanine) delivery to the liver [7]. Recent studies have shown, however, that glucogenesis in the starved dog is unaffected by DCA
[8]. In an effort to learn more about the mechanisms through which DCA leads to the reduction of blood glucose levels in diabetic animals, we have studied the acute effects of DCA on the synthesis and turnover of glucose in the depancreatized dog.

\section{Methods}

\section{Preparation of animals}

Mongrel female dogs weighing from 10 to $15 \mathrm{~kg}$ were depancreatized under sodium pentobarbital anaesthesia and immediately thereafter were maintained on insulin ( 7 units NPH/day) and antibiotic therapy. A minimum of 1 week was allowed for recovery from surgical stress, when antibiotic therapy was discontinued.

\section{Materials}

DCA was obtained from Tokyo Kogyo, Tokyo, Japan. Insulin was obtained from local pharmacy stores. Radio-labelled glucose was obtained from New England Nuclear, Boston, Massachusetts, USA.

\section{Procedures}

Studies were begun at $09.00 \mathrm{~h}$ on unanaesthetized dogs that had been fasted overnight and had received their last insulin $36 \mathrm{~h}$ previously. An intravenous catheter was placed in the saphenous vein of each 
hind limb while the animals were at rest in a Pavlov sling. At the zero time of each study a single intravenous injection of radio-labelled glucose (either $15 \mu \mathrm{Ci}$ of $6-{ }^{14} \mathrm{C}$ glucose given alone, or $15 \mu \mathrm{Ci}$ of $6{ }^{3} \mathrm{H}$ glucose together with $15 \mu \mathrm{Ci}$ of $\mathrm{U}-{ }^{14} \mathrm{C}$ glucose) was made through one of the indwelling catheters in order to label the body glucose pool. Blood sampling was begun $15-30 \mathrm{~min}$ thereafter. Five ml of blood, drawn without stasis, were transferred rapidly into a measured quantity of perchloric acid to precipitate the blood proteins. In all studies a minimum of four samples were taken over an initial period of $1-2 \mathrm{~h}$. DCA $(180 \mathrm{mg} / \mathrm{kg}$ in $10 \mathrm{ml}$ saline) or $10 \mathrm{ml}$ saline was then administered IV at $2 \mathrm{ml} / \mathrm{min}$ and blood sampling was resumed until the end of study.

\section{Analytical Methods}

Glucose, lactate and alanine concentrations were determined with glucose oxidase [11], lactate dehydrogenase [12] and alanine dehydrogenase [13], respectively. The specific activity of glucose in the protein-free filtrates was determined after each filtrate had been passed successively over Dowex $50 \times 8$ ion-exchange resin to remove alanine and Dowex $1 \times 8$ to remove lactic acid and pyruvic acid. The ion-exchanged filtrates containing $6-{ }^{3} \mathrm{H}$ glucose were lyophilized to complete dryness in order to remove ${ }^{3} \mathrm{H}_{2} \mathrm{O}$, a product of labelled glucose metabolism. These samples were then taken up in small quantities of water for glucose assay and liquid scintillation counting. The ion-exchanged filtrates containing $6-{ }^{14} \mathrm{C}$ glucose were reduced in volume and then subjected to periodate oxidation for the independent determination of the carbon 6 and carbons $1-5$ of the glucose molecule [14]. The end product of carbon 6 oxidation, formaldehyde, was then complexed with Dimedon (5,5-dimethyl-1,3-cyclohexanedione) reagent, collected on filter paper, dried, weighed and transferred quantitatively with toluene washing to liquid scintillation vials for counting. $\mathrm{CO}_{2}$ derived from carbons $1-5$ of glucose was collected in $\mathrm{NaOH}$, precipitated as $\mathrm{BaCO}_{3}$, collected on filter papers, weighed and quantitatively transferred to liquid scintillation mixtures containing a thixotrophic gel to suspend $\mathrm{BaCO}_{3}$. The initial specific activity of glucose (obtained by extrapolation of the glucose-specific activitytime curve to zero time), the quantity of isotope injected and the initial glucose concentration were used to estimate the glucose pool size and space [15]. Formulae developed by Medes et al. [16] and later modified by Dunn et al. [17] were used for the calculation of glucose entry and removal from the circulation. During steady state conditions, the equation for glucose turnover is:

turnover rate $=(\mathrm{G} / \mathrm{t}) \mathrm{S}$. $1 \mathrm{n}\left(\mathrm{Sa}_{\mathrm{c}} / \mathrm{Sa}_{\mathrm{t}}\right)$

where $G$ is the glucose concentration, $S$ is the glucose space and $\mathrm{Sa}_{\circ}$ and $\mathrm{Sa}_{\mathrm{t}}$ are the initial and final glucose specific activities over the period of estimation, $t$.

In the post-DCA non-steady-state period, when the blood glucose levels were declining, glucose entry rate (ER) was calculated from the expression:

entry rate $=\frac{\left(\mathrm{G}_{0}-\mathrm{G}_{\mathrm{t}}\right) \mathrm{S} \cdot \ln \left(\mathrm{Sa}_{0} / \mathrm{Sa}_{\mathrm{t}}\right)}{\mathrm{t} \cdot \ln \left(\mathrm{G}_{\mathrm{o}} / \mathrm{G}_{\mathrm{t}}\right)}$

and glucose removal rate from the blood was calculated from the expression:

removal rate $=\frac{\left(G_{0}-G_{t}\right) S+E R}{t}$

where $G_{o}$ is the initial glucose concentration and $G_{t}$ is the glucose concentration at time t.

Studies were carried out, as noted above, with either $6 \cdot{ }^{14} \mathrm{C}$ glucose or a combination of ${ }^{3} \mathrm{H}$ glucose and $\mathrm{U}^{14} \mathrm{C}$ glucose. The use of glucose-specific activities in the formula above excludes recycling components. The ${ }^{3} \mathrm{H}$ label of the $6-{ }^{3} \mathrm{H}$ glucose is lost in the process of glucogenesis, and the $6-{ }^{14} \mathrm{C}$ label that does recycle in glucogenesis is quantitated and mathematically subtracted following the analytical procedure of periodate oxidation of the glucose molecule.

Quantitation of the extent of recycling of the glucose molecule in these studies was made using the formula of Katz et al. [18].

Fraction recycled $=\frac{R_{3_{H}}-R_{14_{c}}}{R_{3_{H}}}$

where $R_{3 H}=$ the apparent replacement rate of glucose measured with ${ }_{6-}^{3} \mathrm{H}$ glucose and $R_{14 \mathrm{C}}=$ the apparent replacement rate of glucose measured with $\mathrm{U}_{-14}{ }^{14} \mathrm{C}$ glucose. For studies carried out with $6-{ }^{14} \mathrm{C}$ glucose, $R_{3_{\mathrm{H}}}$ is derived from the specific activity of $6-{ }^{14} \mathrm{C}$ glucose with the recycling component subtracted, and $R_{14_{C}}$ is derived from the specific activity of $6-{ }^{14} \mathrm{C}$ glucose with the recycling component included.

\section{Results}

Figure 1 illustrates the effect of DCA on the time course of glucose concentration and specific activity $\left(\mathrm{Sa}_{3_{H}}\right)$ and the time course of the concentrations of lactic acid and alanine observed in $\operatorname{dog} 3$. Figure 2 illustrates the same data observed in a placebo study of $\operatorname{dog} 7$. Similar data were obtained from the other experiments. Figure 1 shows the changes in the kinetic parameters of glucose and its precursors, alanine and lactic acid, that occurred following the administration of DCA, while Figure 2 documents the continued steady state of these metabolic pools following saline administration. Table 1 shows that glucose concentration fell 15\%, while both alanine and lactate concentrations fell approximately 50\%. The limited number of observations of alanine concentration preclude significance testing, but the decline in lactate concentration is highly significant $(p<0.001)$. From the data on glucose concentration and specific activity versus time (Figs. 1 and 2), we have made quantitative estimates of glucose turnover (entry and removal) before and after injection of DCA or saline in all studies. After DCA administration glucose concentrations declined and then plateaued between 1.5 and $3 \mathrm{~h}$ following DCA. The kinetic parameters of the glucose system, the rates of glucose entry and removal, are listed in Table 2 as 'pre-treatment steady-state turnover rate'. No alterations from the steady state were observed in the placebo studies and accordingly pre- and post-placebo kinetics in these animals are listed as steady-state turnover rates. In the DCA studies, however, there was an almost immediate decline $(52 \%)$ in the rate of glucose entry into the glucose pool, while at the same time the rate of glucose removal declined by $21 \%$. When a steady state was re-established at the lower glycaemic levels, mean glucose entry and removal rates were $94 \mathrm{mg} \cdot \mathrm{kg}^{-1} \cdot \mathrm{h}^{-1}$. It is clear that the hypoglycaemic action of DCA is initiated by a decreased hepatic glucose supply, since in no case did the immediate postDCA removal rate exceed the turnover rate of glucose established before DCA administration.

To evaluate glucose supply more completely, we have estimated the rate of glucose carbon recycling before and after drug administration. Figure 3 illustrates the data used for these calculations and Table 3 lists the rates of glucose recycling calculated from these data. Glucose carbon recycling averaged $32 \%$ before DCA versus an average of $20 \%$ after drug administration. These data are likely to underestimate recycling (glucose synthesis through lactate) by $50 \%$ due to carbon dilution in the oxalacetate pool $[19,20]$; allowing for this, we estimate that glucose synthesis from lactate would amount to approximately $99 \mathrm{mg} \cdot \mathrm{kg}^{-1} \cdot \mathrm{h}^{-1}$ before and approximately $37 \mathrm{mg} \cdot \mathrm{kg}^{-1} \cdot \mathrm{h}^{-1}$ after DCA. This cal- 


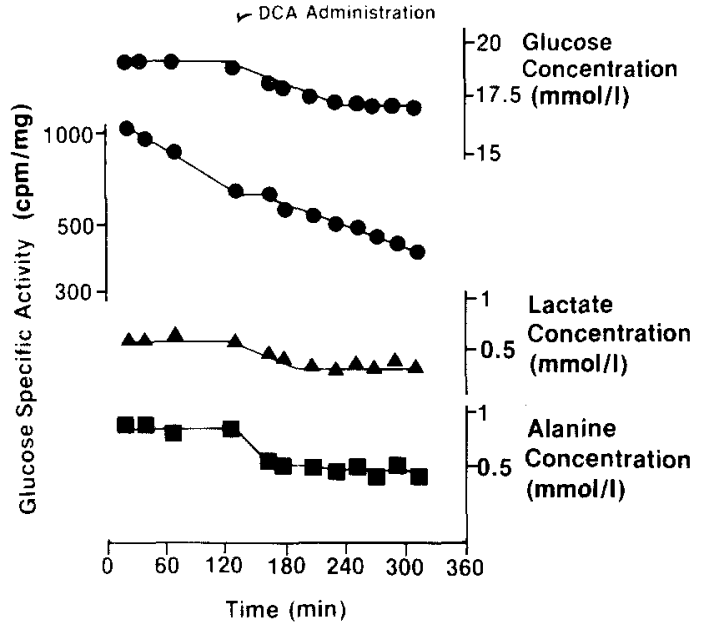

Fig. 1. The effect of DCA on blood glucose ( ), lactate ( $)$ and alanine ( $)$ concentrations and on glucose specific activity (log scale) (O) in the diabetic dog

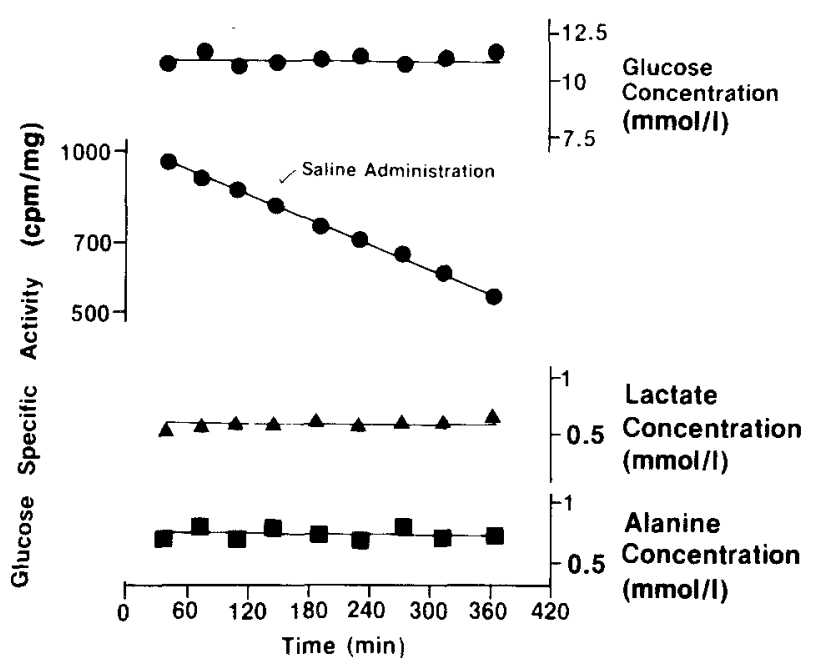

Fig. 2. The effect of saline (placebo) administration on blood glucose (O), lactate (A) and alanine ( $\boldsymbol{\square})$ concentrations and on glucose specific activity $(\log$ scale $)(\mathbf{O})$ in the diabetic dog

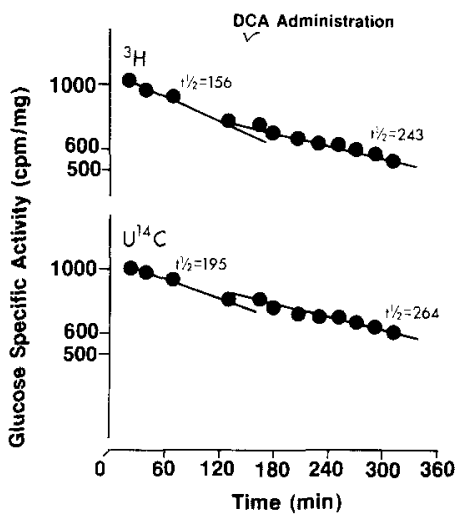

Fig.3. The effect of DCA on the time course of ${ }^{3} \mathrm{H}$ and ${ }^{14} \mathrm{C}$ glucose specific activities (log scales) in the diabetic dog. $t^{1 / 2}=$ half-time (min) of specific activity decline
Table 1. Acute effects of DCA on glucose and glucogenic substrates in the depancreatized dog

\begin{tabular}{|c|c|c|c|c|}
\hline $\begin{array}{l}\text { Animal } \\
\text { number }\end{array}$ & Drug & Substrate & $\begin{array}{l}\text { Before drug } \\
(\mathrm{mmol} / \mathrm{l})\end{array}$ & $\begin{array}{l}\text { After drug } \\
(\mathrm{mmol} / \mathrm{l})\end{array}$ \\
\hline $\begin{array}{l}1 \\
2 \\
3 \\
4 \\
5 \\
\text { Mean }\end{array}$ & DCA & Glucose & $\begin{array}{l}11.8 \\
12.0 \\
12.3 \\
19.0 \\
\frac{13.7}{13.7} p<0.05\end{array}$ & $\begin{array}{r}8.6 \\
9.9 \\
11.5 \\
17.2 \\
11.1 \\
11.6\end{array}$ \\
\hline $\begin{array}{l}6 \\
7 \\
8 \\
\text { Mean }\end{array}$ & Placebo & Glucose & $\begin{array}{l}10.9 \\
10.7 \\
\frac{12.0}{11.2}\end{array}$ & $\begin{array}{l}11.5 \\
10.6 \\
\frac{11.4}{11.1}\end{array}$ \\
\hline $\begin{array}{l}3 \\
4 \\
\text { Mean }\end{array}$ & DCA & Alanine & $\begin{array}{l}0.86 \\
0.65 \\
0.76\end{array}$ & $\begin{array}{l}0.39 \\
0.37 \\
0.38\end{array}$ \\
\hline 7 & Placebo & Alanine & 0.79 & 0.71 \\
\hline $\begin{array}{l}1 \\
2 \\
3 \\
4 \\
5 \\
\text { Mean }\end{array}$ & DCA & Lactate & $\begin{array}{l}0.59 \\
0.83 \\
0.92 \\
0.72 \\
0.90 \\
0.79 p<0.001\end{array}$ & $\begin{array}{l}0.22 \\
0.43 \\
0.59 \\
0.32 \\
0.43 \\
0.40\end{array}$ \\
\hline $\begin{array}{l}6 \\
7 \\
8 \\
\text { Mean }\end{array}$ & Placebo & Lactate & $\begin{array}{l}0.56 \\
0.69 \\
0.71 \\
0.65\end{array}$ & $\begin{array}{l}0.59 \\
0.56 \\
0.83 \\
0.66\end{array}$ \\
\hline
\end{tabular}

Table 2. Glucose kinetics: Effects of dichloroacetate in the depancreatized dog

\begin{tabular}{lllll}
\hline $\begin{array}{l}\text { Treatment } \\
\text { group }\end{array}$ & $\begin{array}{l}\text { Ani- } \\
\text { mal } \\
\text { num- } \\
\text { ber }\end{array}$ & $\begin{array}{l}\text { Steady state } \\
\text { pre-treatment } \\
\text { turnover rate } \\
\left(\mathrm{mg} \cdot \mathrm{kg}^{-1}\right. \\
\left.\cdot \mathrm{h}^{-1}\right)\end{array}$ & $\begin{array}{l}\text { Non-steady } \\
\text { state entry } \\
\text { rate } / \text { removal } \\
\text { rate }\left(\mathrm{mg} \cdot \mathrm{kg}^{-1}\right. \\
\left.\cdot \mathrm{h}^{-1}\right)\end{array}$ & $\begin{array}{l}\text { Steady state } \\
\text { post-treatment } \\
\text { turnover rate } \\
\left(\mathrm{mg} \cdot \mathrm{kg}^{-1}\right. \\
\left.\cdot \mathrm{h}^{-1}\right)\end{array}$ \\
\hline DCA & 1 & 161 & $27 / 118$ & 86 \\
& 2 & 141 & $88 / 115$ & 119 \\
& 3 & 136 & $92 / 134$ & 71 \\
& 4 & 151 & $57 / 81$ & 103 \\
& 5 & $\underline{170}$ & $\underline{103 / 153}$ & 89 \\
\hline Placebo & 6 & 139 & $73^{\mathrm{a}} / 120^{\mathrm{b}}$ & 9 \\
& 7 & 164 & & $144^{\mathrm{a}}$ \\
& 8 & $\frac{157}{153}$ & & 156 \\
& Mean & 152 & & 144 \\
\hline
\end{tabular}

${ }^{a} p<0.01$ compared with steady state pre-treatment turnover rate

b $p<0.05$ compared with steady state pre-treatment turnover rate

Table 3. Glucogenesis: effects of dichloroacetate in the depancreatized dog

\begin{tabular}{|c|c|c|c|}
\hline \multirow{2}{*}{$\begin{array}{l}\text { Treatment } \\
\text { group }\end{array}$} & \multirow{2}{*}{$\begin{array}{l}\text { Animal } \\
\text { number }\end{array}$} & \multicolumn{2}{|l|}{ Glucogenesis } \\
\hline & & $\begin{array}{l}\text { Pre-treatment } \\
\left(\mathrm{mg} \cdot \mathrm{kg}^{-1} \cdot \mathrm{h}^{-1}\right)\end{array}$ & $\begin{array}{l}\text { Post-treatment } \\
\left(\mathrm{mg} \cdot \mathrm{kg}^{-1} \cdot \mathrm{h}^{-1}\right)\end{array}$ \\
\hline DCA & $\begin{array}{l}2 \\
3 \\
4 \\
5 \\
\text { Mean }\end{array}$ & $\begin{array}{l}56 \\
53 \\
30 \\
\frac{61}{50} p<0.01\end{array}$ & $\begin{array}{r}18 \\
21 \\
8 \\
20 \\
17\end{array}$ \\
\hline Placebo & $\begin{array}{l}6 \\
7 \\
8 \\
\text { Mean }\end{array}$ & $\begin{array}{l}15 \\
59 \\
50 \\
41\end{array}$ & $\begin{array}{l}16 \\
56 \\
46 \\
39\end{array}$ \\
\hline
\end{tabular}


culated decline of $62 \mathrm{mg} \cdot \mathrm{kg}^{-1} \cdot \mathrm{h}^{-1}$ in glucose synthesis closely approaches the absolute decline observed in glucose supply $\left(58 \mathrm{mg} \cdot \mathrm{kg}^{-1} \cdot \mathrm{h}^{-1}\right)$. Thus, all of the reduction in glucose supply following DCA could result from inhibition of glucose synthesis from lactate and precursors that cycle through the lactate-pyruvate pool.

\section{Discussion}

Acceleration of glucose oxidation, demonstrated in early studies by Stacpoole and Felts [2, 3], was proposed as a basis for the hypoglycaemic action of DCA. The concomitant inhibition of NEFA oxidation together with lowered levels of muscle citrate suggested that the mechanism for the increased glucose oxidation might involve inhibition of NEFA oxidation which, in turn, would lead to a reduction in muscle citrate levels thereby allowing a disinhibition of phosphofructokinase. Observations similar to those cited above were made by McAllister et al. [4] in studies on rat diaphragm and heart in vitro and on dog heart in vivo. Changes in other metabolite concentrations, however, led these investigators to the conclusion that DCA acted by direct stimulation of pyruvate oxidation. Subsequently Whitehouse and Randle [5] demonstrated that DCA directly activated pyruvate dehydrogenase. Later studies by Blackshear et al. [6] demonstrated that DCA lowered blood glucose in the starved rat and these investigators argued that deprivation of glucogenic substrate rather than the acceleration of glucose utilization was the mechanism responsible for the hypoglycaemia. Recent studies in the starved dog, while showing reductions in circulating alanine and lactate following infusion of DCA, did not demonstrate a reduction in glucogenesis or in the concentration of circulating glucose [8]. In the turnover studies reported here, we have shown an acute and significant reduction in the rate of glucose supply to the circulation following DCA administration to diabetic dogs. Both alanine and lactate concentrations were dramatically reduced. ${ }^{14} \mathrm{C}$ tracer data indicated that glucose synthesis from lactate was reduced by $63 \%$. With a correction for the loss of ${ }^{14} \mathrm{C}$ in the oxaloacetate pool [9], we have calculated that the reduction in glucose synthesis from lactate closely matches the quantitative reduction in the rate of glucose supply to the circulation. Although removal of glucose from the circulation declined in these studies following the administration of DCA, we did not quantitate the loss of glucose in the urine before and after DCA and cannot, therefore assess to what extent the actual peripheral utilization of glucose may have been affected by DCA. Nevertheless, our data suggest that the acute hypoglycaemic action of DCA is brought about by a curtailment of glucose synthesis and glucose delivery to the circulation.

\section{Acknowledgements}

This work was supported by the Veterans Administration, the American Diabetes Association and the Kroc Foundation.

\section{References}

1. Lorini M, Ciman M (1962) Hypoglycaemic action of diisopropylammonium salts in experimental diabetes. Biochem Pharmacol 11: $823-827$

2. Stacpoole PW, Felts JM (1970) Diisopropylammonium dichloracetate (DIPA) and sodium dichloracetate (DCA). Effect on glucose and fat metabolism in normal and diabetic tissue. Metabolism 19: 71-78

3. Stacpoole PW, Felts JM (1971) Diisopropylammonium dichloroacetate, Regulation of metabolic intermediates in muscle of alloxan diabetic rats. Metabolism 20:830-834

4. McAllister A, Allison SP, Randle PJ (1973) Effects of dichloroacetate on the metabolism of glucose, pyruvate, acetate, 3-hydroxybutyrate and palmitate in rat diaphragm and heart muscle in vitro and on extraction of glucose, lactate, pyruvate and free fatty acids by dog heart in vivo. Biochem J 134: 1067-1081

5. Whitehouse S, Randle PJ (1973) Activation of pyruvate dehydrogenase in perfused rat heart by dichloroacetate. Biochem $\mathrm{J}$ 134: $651-653$

6. Alberti KGMM, Holloway PAH (1977) Dichloroacetate and phenformin-induced lactic acidosis. Diabetes 26: 377 (Abstract)

7. Blackshear PJ, Holloway PAH, Alberti, KGMM (1974) The metabolic effects of sodium dichloroacetate in the starved rat: Biochem J 142: 279-286

8. Diamond MP, Rollings RC, Erlendson L, Williams PE, Lacy WW, Rabin D, Cherrington AD (1980) Dichloroacetate: Its in vivo effects on carbohydrate metabolism in the conscious dog. Diabetes 29: 702-709

9. Stacpoole PW, Crofford OB, Oates JA (1976) Treatment of human diabetes mellitus by dichloroacetate. Clin Res 24:30a (Abstract)

10. Stacpoole PW, Moore GW, Kornhauser DM (1978) Metabolic effects of dichloroacetate in patients with diabetes mellitus and hyperlipoproteinemia. N Engl J Med 293: 526-530

11. Barthelmai W, Czok R (1962) Enzymatische Bestimmungen der Glucose in Blut, Liquor und Harn. Klin Wochenschr 40: 585-589

12. Loomis ME (1961) An enzymatic fluorimetric method for the determination of lactic acid in serum. J Lab Clin Med 47:966-969

13. Williamson DH (1974) L-alanine determination with alanine dehydrogenase. In: Bergmeyer $\mathrm{H}$ (ed) Methods of enzymatic analysis. Academic Press, New York, p 1679

14. Reichard GA Jr, Moury NG, Hochella NL, Patterson AL, Weinhouse S (1963) Quantitative estimation of the Cori cycle in the human. J Biol Chem 238: 495-501

15. Searle GL (1976) The use of isotope turnover techniques in the study of carbohydrate metabolism in man. Clin Endo Metab 5: 783-804

16. Medes G, Floyd NF, Weinhouse S (1946) Fatty acid metabolism IV ketone bodies as intermediates of acetate oxidation in animal tissues. J Biol Chem 162: 1-9

17. Dunn DF, Friedman B, Mass AR, Reichard G, Weinhouse S (1956) Effects of insulin on blood glucose entry and removal rates in normal dogs. J Biol Chem 225: 225-231

18. Katz J, Rostami H, Dunn A (1974) Evaluation of glucose turnover, body mass and recycling with reversible and irreversible tracers. Biochem J 142: 161-170

19. Krebs HA, Hems R, Weidmann MJ, Speake RN (1966) The fate of isotopic carbon in kidney cortex synthesizing glucose from lactate. Biochem J 101: 242-249

20. Hetenyi G Jr (1979) Correction factor for the estimation of plasma glucose synthesis from the transfer of ${ }^{12} \mathrm{C}$ atoms from labeled substrates in vivo. Canad J Physiol Pharmacol 57: 767-770

Received: 2 January 1981

and in revised form: 1 March 1982

Gilbert L. Searle, Ph.D.

151-G-2

Veterans Administration Medical Center

San Francisco, CA 94121, USA 